\title{
FRONTEIRAS INDISTINTAS: espaço e tempo no trabalho de tecnologia da informação (TI) ${ }^{1}$
}

\section{INDISTINCT FRONTIERS: space and time in the information technology work (IT)}

\author{
Daniela Ribeiro de Oliveira ${ }^{*}$ \\ Aline Suelen Pires ${ }^{\star *}$ \\ Amanda Coelho Martins ${ }^{* * *}$
}

\section{Resumo}

No contexto do trabalho flexível, novos espaços de trabalho são construídos, sejam físicos, sejam virtuais. Nesse sentido, o setor de tecnologia da informação (TI) apresenta-se como uma categoria privilegiada para a compreensão dos discursos e práticas em relação ao trabalho em home office. Valores como responsabilidade, autonomia, liberdade, iniciativa e confiança passam a ser mobilizados no processo de gestão e produção, tendo as fronteiras entre trabalho e vida "borradas". Com base em entrevistas semiestruturadas, realizadas com trabalhadores de TI do estado de São Paulo, os quais trabalham total ou parcialmente fora dos limites da empresa-cliente, o artigo analisará alguns aspectos do home office a partir da vivência cotidiana desses trabalhadores, problematizando discursos que tendem a tornar evidentes apenas as feições (aparentemente) positivas dessa modalidade de trabalho.

Palavras-chave: Home office. Teletrabalho. Trabalho flexível. Trabalhadores de TI.

\begin{abstract}
In the context of flexible work, new work spaces are built, whether physical or virtual, in that sense the information technology (IT) sector introduces itself as a privileged category for understanding the discourses and practices in relation to work in home office. Values such as responsibility, autonomy, freedom, initiative and confidence become mobilized in the
\end{abstract}

\footnotetext{
1 Uma versão preliminar deste artigo foi apresentada no GT Trabalho e Sindicalismo do VI Seminário de Sociologia e Política da Universidade Federal do Paraná, em maio de 2015.

* Doutoranda do programa de pós-graduação em Sociologia da UFSCar (PPGS-UFSCar), Brasil. E-mail: danicso02@gmail.com

** Pós-doutoranda do Departamento de Sociologia da UFSCar (PPGS-UFSCar), Brasil. E-mail: aline. sociologia@gmail.com

*** Mestranda do programa de pós-graduação em Sociologia da UFSCar (PPGS-UFSCar), Brasil. E-mail: amanda_cmartins@hotmail.com
} 
management and production process, and work and life has its blurred borders. Based on semi-structured interviews with state IT workers in São Paulo state, working fully or partially outside the company-customer limits, we will analyze some aspects of the home office from the everyday life of these workers, questioning speeches that tend to show only the positive features (apparently) of this type of work.

Keywords: Home office. Teleworking (telecommuting). Flexible working. IT workers.

\section{Introdução}

O presente artigo tem como proposta discutir alguns aspectos fundamentais do trabalho em home office ou teletrabalho, buscando problematizar uma visão que vem ganhando espaço nos meios midiáticos e que se caracteriza por "positivar" essa forma de trabalho. A partir das experiências de trabalhadores da área de Tecnologia da Informação (TI), pretendemos demonstrar que o home office envolve questões que vão muito além das promessas de liberdade e autonomia comumente aventadas em relação ao trabalho em casa, principalmente no que se refere aos limites entre vida e trabalho.

A relevância das tecnologias informacionais na vida dos indivíduos tem mobilizado o interesse, na Sociologia do Trabalho, em compreender como se dá o processo e a organização do trabalho dos profissionais de tecnologia da informação. A categoria TI é abrangente, e nasce a partir da autonomização do setor de desenvolvimento de software em relação ao setor de hardware ${ }^{2}$. Compreende diversas atividades relacionadas ao manejo de informações (sua aplicação, produção, armazenamento, transmissão, acesso, segurança), a partir de recursos de computação, na busca de soluções para os fins mais diversos.

Nossa atenção, aqui, estará voltada mais especificamente para os profissionais que trabalham totalmente ou parcialmente fora dos limites da empresa-cliente, os teletrabalhadores ou trabalhadores em home office, como mencionamos. Entre os tipos de profissionais selecionados estão: os trabalhadores de criação ou gestão de tecnologias informacionais, aqueles que desenvolvem softwares ou programas computacionais, criam e administram páginas web, analistas de sistema, gerentes de projetos, consultores de TI, especialistas em bancos de dados, entre outros.

Apesar de o trabalho remoto ou home office estar presente também em ocupações como o teleatendimento ou televendas - que se tornam possíveis e se expandem em decorrência das novas tecnologias informacionais -, consideramos que o perfil do profissional envolvido nesse tipo de atividade difere substancialmente dos demais profissionais de TI citados na pesquisa. Primeiramente, essa diferença se

2 De maneira simplificada, Cocco e Vilarim (2009) definem hardware como sendo a parte física das máquinas, que podem ser programadas para executar ações diferentes, enquanto que o software (ou programa) seria justamente a parte lógica responsável por fornecer instruções de execução para o hardware. 
dá em termos de qualificação (formal ou informal), mas há também discrepâncias em termos de organização do trabalho. Segundo Braga (2009), a organização do trabalho no teleatendimento/telemarketing associa tecnologia da informação com formas tayloristas de produção (fragmentação e controle sobre o trabalho), justificando o uso do termo "infoproletários" para os profissionais desse segmento.

Assim como os trabalhadores de TI, diversas outras categorias profissionais consideradas "não-clássicas" apresentam características semelhantes ao trabalho de desenvolvimento de tecnologias, naquilo que se refere à deslocalização do trabalho e ao imbricamento entre tempo de trabalho e não trabalho. Abílio (2011) realizou uma pesquisa de fôlego com revendedoras de cosméticos da empresa Natura, na qual analisou o trabalho de mulheres revendedoras, observando o processo de flexibilização do trabalho. As novas formas de desregulação, a fronteira tênue entre trabalho e não trabalho e as formas de exploração de um tipo de atividade que é tipicamente feminina no Brasil - são aspectos distintivos do trabalho das revendedoras. Estas trabalhadoras caracterizam-se como um tipo de "proletariado informal", com ausência de vínculos empregatícios, com um elevado número de revendedoras com perfis socioeconômicos diferentes demonstrando que o empreendedorismo não tem um público alvo específico. A pesquisadora assinalou que grande parte das revendedoras têm outras ocupações, como é o caso de uma policial que, além de seu trabalho formal, atua como revendedora da Natura em outros espaços e momentos, sobretudo durante seu tempo de lazer. A indistinção entre tempo de trabalho e não trabalho revela-se neste caso, na medida em que a atividade de revenda não é reconhecida como trabalho.

Os desarranjos do assalariamento e o crescente processo de flexibilização, muitas vezes, confrontam as referências teóricas no que concerne à análise de trabalhos ditos flexíveis. Assim como a pesquisa de Abílio (2011), diversas outras têm sido desenvolvidas com trabalhadores "não-clássicos", é o caso da pesquisa de Pina (2014), que estudou o trabalho dos promoters na cena noturna de São Paulo; de Silva (2014), que analisou o trabalho de designers gráficos - entendido como criativo - e de Martins (2017), que tem se debruçado sobre o trabalho dos estilistas de moda.

Convêm destacar que o enfoque de pesquisa centrou-se nas percepções e experiências dos trabalhadores de tecnologias informacionais, mais precisamente os desenvolvedores de softwares. Decorre dessa perspectiva a elaboração de uma metodologia de investigação que buscou dar voz aos trabalhadores, tomando, portanto, suas experiências narradas como conteúdo principal do material de análise. Assim, para efeito deste artigo, utilizamos como base empírica a análise global de 45 entrevistas com trabalhadores de TI do estado de São Paulo; no entanto, dentre estas, selecionamos para este texto 9 entrevistas com as quais aprofundamos as questões relativas ao imbricamento entre vida e trabalho no contexto do home office praticado no trabalho de desenvolvimento de software. As entrevistas ${ }^{3}$ foram realizadas a partir

3 Esta pesquisa foi desenvolvida no contexto de um projeto temático que envolveu outros dois estudos sobre os trabalhadores de tecnologias informacionais. Foi dividido em eixos temáticos comportando, além do estudo sobre trabalhadores de TI em home office, um estudo sobre a relação entre o trabalho de 
de roteiro semiestruturado, aplicado entre os anos de 2014 e 2016, e foram gravadas com autorização dos entrevistados. O acesso ao campo foi realizado por meio de informante chave (porteiros) e a aplicação do método bola de neve $e^{4}$, encerrando o campo quando este atingiu a saturação qualitativa (GONDIM; LIMA, 2006). Além das entrevistas com trabalhadores, recorremos a outros materiais e documentos que nos auxiliaram na construção do objeto. Desse modo, tomamos o conteúdo e os discursos acerca do home office elaborados e difundidos por meio de sites e blogs. ${ }^{5}$

\section{O home office no trabalho de TI}

Os estudos que se propõem a analisar o trabalho remoto são unânimes em destacar a complexidade em formular uma definição homogênea para a categoria home office - também nomeado de trabalho remoto, teletrabalho, telework, home work (COSTA, 2007; ALVES, 2008; ALEMÃO e BARROSO, 2012). Para Rosenfield e Alves (2011), há uma dificuldade em definir a categoria "teletrabalho" ou home office sem que haja uma construção ideológica da realidade. Assim, segundo a autora, teletrabalho não pode ser considerado simplesmente um sinônimo de trabalho à distância, mas "um elemento das mudanças organizacionais estratégicas que apontam para novas formas de trabalho flexível sustentadas por Tecnologias de Informação e Comunicação" (ROSENFIELD; ALVES, 2011, p. 217). Huws et al. (1999) utilizam como critério para mapeamento dos teletrabalhadores todos aqueles que, ao menos um dia da semana, tem sua casa como base do trabalho.

Dessa forma, entendemos o home office como experiências de trabalhar fora do escritório da empresa para a qual o profissional foi contratado ou para a qual presta serviço e que faz uso de ferramentas de telecomunicação, permitindo o trabalho e a comunicação à distância e possibilitando a troca de dados e informações. Seria problemático utilizar como ponto de partida para a análise uma definição rígida que enquadrasse a modalidade home office exclusivamente como o trabalho realizado no âmbito da casa, pois eliminaria os arranjos de trabalho remoto observados durante a pesquisa empírica.

Independente da definição, o teletrabalho é uma possibilidade aberta pelos processos de flexibilização do trabalho e desenvolvimento de novas tecnologias, o qual pode contribuir para uma indefinição dos limites entre vida e trabalho e,

\footnotetext{
TI e juventude (Geração Y), desenvolvido como projeto de pós-doutorado; e outro sobre o trabalho de TI e criatividade, desenvolvido num projeto de mestrado. Por esse motivo, optamos por construir coletivamente um único roteiro contendo os temas que perpassaram os três objetivos das pesquisas em curso 4 Trata-se da prática de um informante colocar a pesquisadora em contato com outro entrevistado, este, por sua vez, indica outro entrevistado, e assim sucessivamente até formar uma rede de contatos. 5 Foram utilizados os conteúdos dos seguintes blogs: Go Home, Adoro Home Office e Nômades Digitais. A escolha destes blogs em detrimento de outros responde aos seguintes critérios de relevância: a) tempo de existência dos blogs; b) frequência das atualizações dos conteúdos publicados; c) número de curtidas e/ ou seguidores das páginas escolhidas.
} 
assim, possibilitar o prolongamento das jornadas de trabalho. A lógica do home office sustenta-se em valores como iniciativa, responsabilização, autocontrole e confiança, que caracterizam o chamado "novo espírito do capitalismo" descrito por Boltanski e Chiapello (2009). É a partir dessa perspectiva que pretendemos analisar alguns aspectos do home office, tendo como referência a vivência cotidiana dos trabalhadores de TI, problematizando discursos que tendem a tornar evidentes apenas as feições (aparentemente) positivas desta modalidade de trabalho.

A pesquisa de campo indicou uma diversidade de arranjos do trabalho remoto, dando-se a execução do trabalho em tempo total ou parcial, no espaço da casa, mas também fora dela, em salas de compartilhamento - o chamado coworking ${ }^{6}$. Há casos de empresários ou empregados que exercem suas atividades de trabalho nos escritórios do cliente, do empregador ou no próprio escritório, a depender da relação de trabalho estabelecida entre entrevistado e empresa-cliente. Levar trabalho para casa, ao fim do expediente, alguns dias da semana é mais comum. Nesse caso, os trabalhadores cumprem jornadas de trabalho nos escritórios do empregador ou do cliente e, em determinadas situações, precisam "virar a noite" ou trabalhar a partir de casa, durante os finais de semana, para finalizar os projetos.

Sejam os empregados, sejam os empreendedores ou empresários, o que tem frequentemente aparecido nas entrevistas são relatos que nos levam a interpretar o quão intenso é o trabalho para essa categoria. Muitas vezes naturalizada por parte dos entrevistados, a intensidade é marcada pela quantidade de trabalho, prazos apertados, pressão para cumprimento dos objetivos e necessidades de clientes. A dificuldade de pôr limites na duração do trabalho, quando este é realizado a partir de casa, é discurso que culpabiliza o trabalhador que possui grande parte do controle sobre o seu trabalho. As atividades de trabalho, quando são realizadas em casa, geralmente são interpretadas, por alguns dos trabalhadores, como possibilidade de tempo ganho em relação à ausência de deslocamentos até o escritório, interrupções para atender telefones, paradas para reuniões etc. Mas, na prática, esse tempo ganho, muitas vezes, é convertido em trabalho intensificado.

Modalidade de trabalho que se desenvolve a partir do surgimento da empresa integrada em rede, decorrente do processo de reestruturação capitalista e de flexibilização das relações de trabalho, o teletrabalho é, portanto, resultado

6Coworking é um termo descrito pela primeira vez pelo designer Bernie DeKoven, em 1999, relacionando-o a uma dinâmica ou forma de trabalhar e não a uma plataforma de trabalho, como passou a se referir posteriormente. Desde 2005, quando foi criado o primeiro escritório - Hat Factory - cujo objetivo foi reunir profissionais de tecnologia da informação com diferentes projetos e que não estavam associados entre si como empresas, o termo passa a referir-se a escritórios ou espaços de compartilhamentos de trabalho. Esses espaços de compartilhamento apresentam composições variadas, com a presença de profissionais submetidos a diferentes tipos de vínculos de trabalho e diferentes profissionais (freelancers, empresários e autônomos) que deixaram seus escritórios em casa para trabalhar nesse ambiente compartilhado. O coworking está associado aos processos e dinâmicas da flexibilidade que orientam o modo de produção e as formas de organização do mundo do trabalho (ZANON, 2015, p. 1819). 
das necessidades deste modelo de empresa e não consequência direta e necessária da tecnologia disponível. Três tipologias foram desenvolvidas a fim de designar diferentes formatos de teletrabalho: a) os substituidores: refere-se àqueles trabalhadores que substituem os serviços realizados em um espaço de trabalho tradicional pelo serviço realizado em casa; b) os autônomos, que trabalham on-line de casa; e c) os complementadores, trabalhadores que levam para suas casas trabalho do escritório para concluir ou continuar trabalhando em casa (CASTELLS, 1999, p. 404).

Sennett (1999), ao problematizar os significados e efeitos do capitalismo flexível sobre o modo como os trabalhadores passam a construir suas narrativas pessoais - fundada na lógica da fluidez do tempo, da recusa à padronização e burocratização -, chama atenção para as experiências contemporâneas em relação ao tempo. Para o autor:

As organizações flexíveis hoje estão fazendo experiências com vários horários do chamado "flexitempo". Em vez de turnos fixos, que não mudam de mês para mês, o dia de trabalho é um mosaico de pessoas trabalhando em horários diferentes, mais individualizados [...]. Esse mosaico de tempo de trabalho parece distante da monótona organização do trabalho na fábrica de alfinetes; na verdade, parece uma liberação do tempo de trabalho, um verdadeiro benefício do ataque da organização moderna à rotina padroniza. As realidades do flexitempo são bem diferentes (SENNETT, 2009, p. 66).

O construto em torno do home office ou trabalho remoto é atravessado por outros aspectos relacionados à organização e as relações de trabalho. Trabalham em casa tanto empregados - portanto regulados pela CLT - quanto os chamados empreendedores, empresários ou PJ (pessoa jurídica) e os autônomos/ freelancers. É nesse sentido que Rosenfield (2011) - tendo como referências estudos da Organização Internacional do Trabalho (OIT) - apontou a necessidade de considerar, além dos aspectos relativos à regulação, o local/espaço de trabalho, o horário/tempo de trabalho (tempo integral ou parcial) e as competências requeridas (conteúdo do trabalho), como outras dimensões que colaboram com o enquadramento do teletrabalho.

Assim, a combinação do teletrabalho com determinados tipos de contrato e níveis de qualificação pode resultar em diferentes graus de precariedade do trabalho. A situação de um trabalhador home office contratado como PJ, que exerce uma atividade que exige menor grau de formação e que trabalha por projetos, pode ser muito mais precária e marcada por diversos tipos de instabilidade quando comparada com a de outro profissional que tem um contrato de trabalho CLT, ocupa uma função que exige alto grau de qualificação e tem um bom salário, mas também trabalha em casa. No entanto, ambos podem ter seu trabalho intensificado e suas jornadas estendidas em razão de trabalharem fora do ambiente da empresa-cliente.

Como mencionamos a questão da qualificação, vale fazermos uma ressalva em relação à área de TI, que é válida também para outras áreas caracterizadas por constantes transformações. Em um contexto de incertezas e transitoriedades, as 
capacitações têm uma duração cada vez menor, e as empresas passam a buscar trabalhadores altamente capazes de um aprendizado constante (SENNETT, 1999). O diploma não figura mais como garantia exclusiva de bom emprego e sucesso profissional. Assim, a capacidade de adquirir novos conhecimentos foi constantemente apontada pelos trabalhadores entrevistados como uma das principais (senão a principal) qualidades que um profissional deve demonstrar para permanecer na área. "É uma profissão que você nunca pode parar de estudar" (Eric), pois "cada dia tem que se reinventar, ser um profissional diferente" (Leonardo), " $a$ pessoa tem que gostar de sempre estar aprendendo" (Cristiano), "é um trabalho para pessoas atualizadas" (Thiago). São falas comuns entre os entrevistados e reforçam essa ideia de que existe uma necessidade incessante de renovação dos conteúdos aprendidos.

Em áreas como a de TI, podemos encontrar tanto profissionais altamente qualificados como jovens talentos que são reconhecidos por possuírem alto grau de conhecimento - em alguma área ou ferramenta - adquirida de forma autodidata, em interação com um instrumental disponível na internet. Nesse sentido, o "aprender fazendo" ganha uma dimensão fundamental e o trabalhador jovem, supostamente mais "antenado", móvel e flexível, também passa a ser valorizado (PIRES, no prelo). No entanto, uma consequência dessa mobilidade, em especial no que se refere à obtenção constante de novos conhecimentos, é que, em muitos casos, os profissionais da área sentem-se, desde muito cedo, "envelhecidos" e cansados demais para permanecer na carreira, buscando alternativas que vão desde uma reorientação para atividades consideradas mais "leves" em TI até a saída definitiva da área (PIRES, 2016).

\section{A “numerologia” das dicas e a difusão do home office nas mídias}

A realização do trabalho remoto desencadeou uma série de publicações que difundem o home office como uma prática que permitiria aos trabalhadores conciliarem seu tempo de trabalho com a vida privada. Identificamos um conjunto de textos midiáticos, disponibilizados em blogs, revistas e livros, que oferecem "dicas" e estratégias aos profissionais e/ou gestores de empresas sobre como manter o foco, como organizar um ambiente adequado para trabalhar remotamente. Argumentamos que tais publicações funcionam como uma espécie de manual de boas práticas sobre auto-organização, para aqueles que desejam adotar o home office como modalidade de organização do tempo de trabalho. Nestas publicações, são representados os perfis considerados adequados de profissionais que podem trabalhar remotamente, além de desenhar um estilo de vida que se justifica a partir do avanço tecnológico, responsável por transformar as formas de entendimento e organização do tempo e espaço.

O conteúdo das publicações é permeado por um caráter motivacional, passando a ideia de que "tudo é possível", que qualquer um pode alcançar a realização profissional, desde que trabalhe naquilo gosta. Os textos mobilizam dimensões subjetivas, tais como: "o amor por aquilo que faz"; "a coragem para 
mudar de trabalho"; "capacidade de enfrentar o risco para atingir os sonhos". Esses elementos operam como estímulo para o trabalhador "descontente" - com seu trabalho tedioso, enfadonho, desmotivador - se movimentar em busca de um trabalho que permita vivenciar o prazer, a diversão, em desenvolver a criatividade. Esses valores são disseminados por meio de textos curtos, linguagem simples, muitos deles em forma de tópicos, informações rápidas e muitas imagens - paisagens, lugares, cidades, espaços internos de escritórios etc.

As mensagens que têm a intenção de convencer seus leitores em busca de mudança são marcadas pelo que chamamos de a "numerologia" das dicas. Tratase de conselhos expressos em títulos tal como: "5 motivos para trabalhar com o que você gosta de verdade"; "4 motivos para questionar os modelos de trabalho tradicionais"; "5 pessoas que largaram tudo para seguir o sonho". Em um dos $b \operatorname{logs} s^{7}$ analisados, difunde-se a proposta do "nomadismo", do desenraizamento possibilitado pelo trabalho remoto. O slogan que o define expressa o objetivo de seus idealizadores por meio da seguinte descrição: "usando a tecnologia para viajar e trabalhar ao mesmo tempo". Trata-se de mobilizar as possibilidades abertas pelas tecnologias informacionais para efetuar a dupla realização de trabalhar no que ama e viajar pelo mundo. Note-se que não se trata de imigração, ou seja, da saída de um país para outro com objetivo de construir uma carreira em local que ofereça melhores oportunidades. Essas mensagens podem, no entanto, produzir um efeito perverso, que é o de mostrar como indivíduos comuns conseguiram trabalhar no que amam e conquistaram a tão sonhada "liberdade", mas como, por outro lado, outros indivíduos, muitas vezes com trajetórias de formação e ocupacionais parecidas, não conseguiram o mesmo resultado. Portanto, só lhes restando o fracasso.

O capital tem mobilizado as subjetividades na constituição de valor e na produção de bens imateriais (LAZZARATO, 2001) e, na esteira da construção de novas subjetividades, difunde-se a ideia de um perfil de profissional capaz de atender ao atual momento do capitalismo. Ou seja, capaz de se adaptar rapidamente às mudanças, que seja móvel, e tenha características de liderança. Como descrevem Boltanski e Chiapello (2009, p. 157), que seja leve, em outras palavras, capaz de renunciar à estabilidade, ao enraizamento, ao apego aos valores e espaços locais, sem amarra, desapegado de tudo quanto possa impedir o movimento, a mobilidade.

A autodisciplina que é exaltada e apontada como condição para o sucesso do trabalho remoto é acionada, tanto pelos entrevistados quanto nos manuais (blogs) de boas práticas de home office, como elemento necessário para cumprir com as obrigações tal qual quando se está no escritório da empresa. É paradoxal a percepção de que trabalhar distante da empresa significa ganhos em termos de controle sobre os tempos de trabalho e vida, quando, na verdade, o que as trajetórias ocupacionais dos entrevistados indicam é que, muitas vezes, trabalha-se mais quando está em casa.

As orientações de boas práticas para o home office estão, a todo momento, informando as regras a serem seguidas pelos trabalhadores, para não "perderem-se" diante da liberdade possibilitada pelo trabalho remoto. Assim, faz parte da lista: acordar

7 Referimo-nos ao blog Nômades Digitais, consultado em: <http://nomadesdigitais.com/>. 
todos os dias no mesmo horário; arrumar-se como se fossem trabalhar fora; estabelecer rotinas (dormir e acordar sempre nos mesmos horários). No limite, o trabalho em casa não implodiu a rotina e a padronização dos tempos, pelo contrário, ela existe, mas sob outro formato, controlada pelo próprio trabalhador. Pode ser até mais rígida e constrangedora que o controle praticado pela supervisão, no interior do escritório.

Santiago (2012) destaca o paradoxo entre ter o teletrabalho como expressão da organização flexível do trabalho de um lado, mas as descrições do perfil de trabalhador desejado e adequado são profundamente rígidas. Para o autor, é projetado um tipo de "teletrabalhador" como alguém disciplinado, capaz de trabalhar isoladamente, com capacidade de organizar-se na ausência constante da supervisão e sem receber feedbacks da equipe. Para além do autocontrole, que está sob o domínio dos profissionais, trabalhar em casa ou fora da empresa-cliente, apesar de parecer propiciar mais liberdade ao trabalhador, também está sujeito às novas e variadas formas de controle, por meio de telefonemas, mensagens intra-rede e e-mails (SENNETT, 1999). Uma das formas de controle percebida como tal pelos entrevistados é a lógica do controle por objetivos e prazos que, em muitos casos, levam o profissional a trabalhar intensamente.

\section{As percepções dos trabalhadores sobre o home Office}

Pretendemos discutir, aqui, alguns aspectos do home office, como a intensidade do trabalho, a relação entre trabalho e vida pessoal, a dimensão da sociabilidade, a questão da autonomia, além da questão de gênero, que é transversal, analisando falas de alguns trabalhadores selecionados a partir da pesquisa de campo.

\section{Intensidade e (in)visibilidade do trabalho}

Joana $^{8}$ é casada, tem 34 anos e não tem filhos. É formada em ciências da computação, cursando MBA em gestão de tecnologia da informação. Sua trajetória ocupacional é marcada por longos períodos de permanência nas empresas onde trabalha - em média, cinco anos em cada uma. Esse aspecto chama atenção pelo fato de estarmos lidando com um setor cuja rotatividade é considerada alta (SOFTEX, 2012). Joana é consultora sênior em uma multinacional de prestação de serviços em TI. Trabalha alocada no cliente - face to face -, o que significa estar o tempo todo no site do cliente, analisando suas dificuldades e implementando tecnologias de gestão de processos.

Apesar da importância do trabalho in loco, em algumas circunstâncias, Joana trabalha em casa. Nessas ocasiões, tem a chance, segundo ela, de realizar seu trabalho

8 Os nomes verdadeiros dos trabalhadores e trabalhadoras foram substituídos, no texto, por nomes fictícios, com o objetivo de preservar a identidade dos entrevistados. Os nomes das empresas onde trabalham também foram omitidos. 
com maior concentração e foco, já que enfrenta poucas interrupções (reuniões e pedidos de ajuda) quando trabalha em casa. O tempo ganho por não precisar deslocar-se até a empresa é destacado em sua narrativa como uma vantagem.

A vantagem que eu vejo [no home office] é a concentração no trabalho que é maior, pelo menos pra mim é maior, eu tenho menos interrupções. Uma grande vantagem é que eu acabo produzindo muito mais porque eu gasto menos tempo no trânsito. Como eu moro um pouco distante de São Paulo, eu acabo, quando tenho que me deslocar até o cliente, perdendo muito tempo no trânsito e aí tempo que eu perco no trânsito quando eu trabalho em casa é tempo produtivo. Essas seriam as vantagens (Paula, 12/09/2014).

É interessante observar a percepção positivada em relação ao trabalho a partir de casa associado ao ganho em produtividade e não como possibilidade de alocar o tempo "ganho" para outros afazeres da vida pessoal. Nesse sentido, o tempo perdido no trânsito com o deslocamento casa-trabalho/trabalho-casa não é convertido em tempo de lazer ou em qualidade de vida, mas em mais trabalho, o que pode resultar em prolongamento da jornada.

Há uma tendência ao prolongamento da jornada do trabalho realizado em casa evidenciado nas falas de outros profissionais, muitas vezes como algo natural, portanto, como parte de uma lógica própria da carreira. Talita tem 26 anos, é casada e sem filhos. Tem curso superior em informática para gestão de negócios e, atualmente, está cursando uma especialização, além de ter realizado outros cursos e obtido certificações técnicas na área. Há quatro anos trabalha numa multinacional, localizada na cidade de São Bernardo do Campo, na região metropolitana de São Paulo, e seus vínculos de trabalho sempre foram de CLT ou estágio. No momento, está trabalhando em casa, na modalidade home office, mas esta é uma condição temporária, pois costuma trabalhar no site da empresa. Não é a primeira vez que trabalha em home office, já esteve nessa condição outras vezes, por demanda da própria empresa, tendo uma experiência considerável nessa modalidade de trabalho. Talita afirma que, quando está trabalhando na empresa, não costuma exceder sua jornada de trabalho diária, mas reconhece que a probabilidade de isso acontecer aumenta quando trabalha em casa:

Quando estou na empresa, não, mas, quando estou em casa, é muito fácil acontecer [estender a jornada]. Porque você pensa: "já estou em casa, não tenho deslocamento, posso ficar até um pouco mais tarde". Às vezes, eu conecto [o computador] mais cedo pra ir pegando os e-mails. (Talita, 24/09/2014).

Vale destacar que nem sempre os trabalhadores reconhecem como trabalho aqueles momentos - por mais breves que sejam - em que, estando de folga ou em períodos de férias, acessam e-mail ou leem mensagens instantâneas a fim de acompanhar ou resolver assuntos relacionados com seu trabalho. Quando perguntamos sobre a possibilidade de realização deste tipo de prática, fora do horário de expediente, ela revelou-se frequente entre os trabalhadores. As narrativas apontam 
para certa conformação em relação a essas práticas, como se não pudessem controlálas. Demonstrando, novamente, tratar-se de uma característica própria da forma de desenvolver o trabalho em TI - colaborativo.

Além de sua jornada normal em home office, uma vez por mês, em um final de semana, Talita fica de plantão. Ela permanece 48 horas em alerta à espera de possíveis telefonemas para solucionar problemas dos clientes - para os quais a empresa presta serviço. Segundo a entrevistada, o plantão lhe causa muito stress e ansiedade, mas é algo que pretende deixar de fazer assim que possível. O esquema de sobreaviso ${ }^{9}$ impõe uma rotina ao trabalhador que, apesar de não estar trabalhando, precisa adequar seu tempo supostamente livre - na verdade está em casa, mas à disposição da empresa - em função dos potenciais chamados para o trabalho (OLIVEIRA; MARTINS, no prelo).

Talita, no entanto, assim como a maioria dos profissionais que compõem a amostra, não deseja trabalhar em casa de forma permanente. Há uma percepção entre esses trabalhadores de que quem trabalha apenas em casa não é "visível" na empresa e, por isso, tem menos possibilidades de reconhecimento profissional, de crescimento na carreira. Afirmam que é raro o caso de promoção de um profissional que trabalha em casa, quando comparado com aquele que está todos os dias na empresa. Em geral, os trabalhadores gostariam de, eventualmente, trabalhar em home office, desde que pudessem, aos menos de vez em quando, ir para a empresa. Talita diz que:

É estranho, mas as pessoas precisam te ver de vez em quando, lembrar-se de você. É uma perda que acontece com quem trabalha de casa. Tanto que eu tento ir pelo menos uma vez a cada quinze dias lá, pelo menos dar um "oi", porque parece que as pessoas realmente esquecem e esse é o problema de trabalhar de casa, mas lógico que tem essas facilidades. Você [quando] fica em casa, não perde tempo para ir e para voltar, se precisou lavar roupa você vai lá e põe a roupa -"rapidinho" - para secar. Mas o ruim é que você, nem sempre, tem horário para jantar, para almoçar. Nem sempre [você] sai no horário certo [da empresa, já que está em casa]. Tem esses problemas, sabe? (Talita, 24/09/2014).

Outro aspecto que chama atenção na fala de Talita é que ela, assim como outras mulheres em situação semelhante, destaca a possibilidade que o home office oferece de conciliar o trabalho com as atividades domésticas. A pesquisa de Castro (2012) apontou que os diferentes arranjos de jornadas e espaços de trabalho têm consequências diferentes para homens e mulheres. Pontuando uma relação entre o

$9 \mathrm{O}$ regime de sobreaviso, estabelecido no artigo 244 da Consolidação das Leis do Trabalho (CLT), é a situação na qual que se encontram os empregados efetivos que, à distancia, permanecem sob controle do empregado, em virtude de estar aguardando chamados do empregador, por instrumentos telemáticos ou informatizados, para realização de serviços (TRIBUNAL SUPERIOR DO TRABALHO, 2015). Trata-se de um benefício que deve ser pago aos trabalhadores que, em períodos de descanso, estão em escala de plantão para o empreendimento. 
trabalho e o desejo de ser mãe, ao estabelecer-se na carreira muitas vezes o desejo da maternidade é adiado e negociado quando o trabalho toma novas formas de organização. O home-office aparece como uma maneira de "realizar desejos", o que pode implicar perdas e a aceitação de uma condição mais precária e instável de trabalho. Para muitas mulheres, o home office aparece como "um instrumento de conciliação entre trabalho e família, traduzido em rebaixamento salarial, completo embaçamento das fronteiras do cuidado e do chamado trabalho produtivo e diminuição da produtividade", enquanto que, para os homens, "era utilizado como mecanismo de realização do trabalho de maneira remota, com as vantagens de maior conforto e maior produtividade" (CASTRO, 2013, p. 307). Além disso, quando a mulher opta pelo home office, pelo fato de que este facilita a conciliação entre o trabalho e os afazeres domésticos/cuidado com os filhos, o que ocorre é uma reprodução dos padrões de gênero e da divisão sexual do trabalho.

Independentemente do local de trabalho, as mulheres são minoria no setor de TI, e sua participação na área não acompanhou o ritmo de crescimento da participação das mulheres no mercado de trabalho, de uma forma geral, nos últimos anos. Além disso, as mulheres ainda parecem sofrer diversas formas de discriminação e preconceitos nesse universo marcadamente masculino, segundo as entrevistas realizadas. Aquelas que pretendem permanecer no campo da tecnologia da informação têm que reafirmar a todo o momento sua presença e sua capacidade de realizar seu trabalho da mesma forma que os homens (CASTRO, 2013).

\section{Quando o trabalho interfere na vida pessoal (ou vice-versa?)}

Lopes tem 25 anos, é casado e tem uma filha. Foi estimulado pela mãe a escolher a carreira de tecnologia, embora gostasse mesmo de filosofia. Iniciou o curso de Tecnologia da Informação, mas não concluiu a graduação, por não concordar com o modelo de ensino. Com perfil autodidata, afirma que sua formação se deu pelas empresas onde esteve empregado ou prestando serviço. Trabalha em São Paulo, em uma pequena empresa, atuando como desenvolvedor e vinculado como PJ. A possibilidade de morar próximo ao local de trabalho alteraria o cotidiano de Lopes, afinal ele reside a duas horas de seu trabalho, utilizando ônibus e trem para o trajeto casa-trabalho e trabalho-casa, restando pouco tempo para ficar com sua família, sobretudo com sua filha - isso aparece em sua narrativa como algo profundamente negativo. Apesar desse cenário, Lopes pondera e aponta preferir trabalhar na empresa, já que a dificuldade em conciliar o trabalho em casa com a família dificulta sua realização.

No meu caso [trabalhar em casa] só quando estou sozinho. Têm a neném e a minha esposa aqui. Elas são terríveis [...] parece que elas veem que se eu estou em casa [acham que] eu não estou trabalhando. É bem difícil isso, não importa o que você esteja fazendo. [...] Para mim é muito difícil [trabalhar quando a família está em casa], eu normalmente prefiro vir para cá para trabalhar [na empresa]. Acontece de eu trabalhar em casa quando elas não estão. Um dia da semana que é mais tranquilo, que uma está trabalhando e a outra está na escolinha, aí rola 
bem, ou de madrugada. Eu prefiro fazer quando as duas estão dormindo que ai eu consigo trabalhar tranquilamente. Mesmo porque, às vezes, já aconteceu de eu trabalhar um fim de semana inteiro em casa, com as duas lá, aí você não consegue trabalhar direito e também não fica com a sua família, daí gera aquele peso na consciência e você fala, poxa "estou aqui, perdi o final de semana inteiro trabalhando e não vivi”, isso passa bastante na cabeça (Lopes, 04/10/2014).

No caso de Lopes, não há uma cobrança por parte da família, mas uma autocobrança em relação ao fato de o trabalho consumir o tempo que deveria ser dedicado para si ou para a família. $\mathrm{O}$ argumento de que a indivisibilidade entre trabalho e vida seria vantajosa para os trabalhadores e para a criatividade das equipes não parece ter se generalizado como algo efetivamente positivo. $\mathrm{O}$ sentimento de culpa, expresso na fala de Lopes, é um indicador da contraposição com percepções que difundem o trabalho em home office como sinônimo de liberdade e controle em relação aos tempos. Indica também o dilema entre atender ao excesso de demandas de trabalho e as possibilidades de desfrutar da vida social.

Não se trata aqui de advogar uma divisão nítida entre tempo de trabalho e não trabalho ou entre trabalho e vida pessoal/lazer, o que seria ingênuo no contexto flexibilização das relações de trabalho. Mas de evidenciar que essa indistinção causa conflitos internos, pois gera, sobre os trabalhadores, sentimento de culpa por não dar atenção à família quando se está trabalhando e culpa por não estar trabalhando quando está com a família ou envolvido em alguma atividade de lazer. Principalmente quando a cobrança sobre o trabalho se dá por meio de metas e resultados. Assim, a suposta "liberdade" de escolher como e quando trabalhar pode se converter em fonte de ansiedade, frustração e culpa. Além disso, é preciso relativizar o discurso de que as formas flexíveis de trabalho, sobretudo teletrabalho, sejam sinônimas de liberdade e autonomia. As novas configurações do trabalho são acompanhadas de novas formas de controle (SENNETT, 1999). O que parece ocorrer, segundo Zarifian (2002), é o controle do engajamento, que se torna possível com a modulação ou flexibilização da utilização do tempo, do espaço e do engajamento subjetivo. O controle deixa de depender da figura do "capataz" para ser exercido através de metas e resultados, possibilidade aberta por meio do uso de novas tecnologias (inclusive informacionais) e do próprio trabalhador, que passa a controlar suas atividades de trabalho.

Enquanto Lopes enfrenta o dilema entre conciliar a longa distância do seu trabalho, realizar outros projetos que desenvolve como free lancer e conciliar seu tempo profissional com a família; Joana parece enfrentar essas questões de forma diferente. É casada com uma pessoa da área de TI. Como ambos conhecem bem a realidade da profissão, vivenciam os limites e as dificuldades, aparentemente sem sentimento de culpa, e declararam não enfrentar problemas em conciliar seus tempos de trabalho e da vida pessoal. Quando precisam trabalhar em casa - o que raramente ocorre -, utilizam um espaço construído para isso, sendo a negociação muito simples, basta um comunicado para evitar interferências. 
Eu tenho uma bancada de trabalho e normalmente não é necessário estratégia [para não ser interrompida]. No caso de eu estar trabalhando em casa e meu esposo também estar em casa, o que normalmente não acontece. Se acontecer eu costumo avisá-lo que eu preciso me concentrar aqui, eu preciso produzir e aí ele respeita esse espaço normalmente. (Paula, 12/09/2014).

Leonardo é casado, tem 28 anos e não têm filhos. Tem ensino superior completo em engenharia elétrica e curso de programação industrial. Sua trajetória ocupacional se inicia em uma empresa de fabricação de laser, onde permaneceu por aproximadamente dois anos. Depois desta experiência, passou por outros três trabalhos, até ser contatado como consultor sênior de TI, pelo atual empregador, há dois anos. Trata-se de uma grande empresa de prestação de serviços, projetos e desenvolvimento de software, localizada em São Paulo (capital). Seu vínculo contratual (CLT) é com esta empresa, mas sua base operacional é no cliente de seu empregador - a sede de um banco.

Para ele, trabalhar em casa assume outro significado, pois nem sempre é produtivo e pode refletir sobre os relacionamentos afetivos. O problema de trabalhar em casa é o impacto sobre o foco, pois há diversas "interferências" e desvios de atenção, no cotidiano da casa, que, muitas vezes, dificulta o foco sobre as atividades. Pode interferir também nos momentos de interação com a esposa, já que nem sempre é rápida a "passagem" entre os temas e problemas relacionados ao trabalho para os temas ou problemas relativos à família, às questões afetivas e vice-versa. Vejamos um trecho da entrevista em que ele descreve essas questões.

[...] às vezes, dá a impressão que você está em casa e não está sendo muito produtivo, às vezes, você está focado. Ou, às vezes, você está estressado com alguma situação e isso vai refletir [no relacionamento], porque você estava naquela situação de stress e logo depois você está com a sua esposa e...opa! Você exagerou em alguma coisa. (Leonardo, 17/07/2014).

As entrevistas têm apontado que os solteiros são os que menos enfrentam problemas em conciliar o trabalho no espaço de casa, mesmo para aqueles que moram com a família ou dividem a casa com colegas (de profissão ou da universidade). Os casais sem filhos - que são a maioria dos entrevistados - também enfrentam menos dificuldades em conciliar a vida pessoal e o trabalho. Nesse sentido, as entrevistas têm indicado uma situação favorável para os solteiros ou casados sem filhos para trabalhar em TI, sobretudo quando as atividades de trabalho se realizam em casa. Apesar disso, não estamos desconsiderando os potenciais conflitos de se ter o trabalho dentro de casa, apontado, por exemplo, por Leonardo.

\section{Tempo livre ou tempo de não trabalho}

Tentar apreender as experiências de "tempo livre", procurando compreender o que é feito com o tempo de não trabalho, tem sido o maior desafio da pesquisa. $\mathrm{O}$ 
que temos identificado, quando perguntamos sobre as atividades realizadas quando não estão trabalhando, ou quando tentamos aprofundar questões relacionadas ao cuidado de si, é que uma lista de espaços frequentados ou eventos vivenciados são relacionados, tal como expresso na narrativa de Leonardo: “[...] uma semana antes eu estava bem ocioso, agora faço um pouquinho de academia, violão, guitarra. Assisto seriado. De final de semana vou à igreja [...]”. Bruno também descreve suas atividades quando encerra a jornada de trabalho:

Bom, para descansar, morando sozinho em São Paulo, sem amigos, sem vida social nenhuma, o meu lazer... era... Ah, e tem que sair do computador, né? Porque não vale chegar em casa e ligar o computador... Bom, o meu lazer era chegar em casa, jantar, tomar um banho, deitar, catar meu celular, ligar na Netflix e assistir série. (Bruno, 20/06/2014).

Mesmo praticando outras atividades cotidianas, os temas relacionados ao trabalho surgem e levam os trabalhadores, muitas vezes, a insights que podem ajudálos a encontrar soluções para problemas do trabalho, que não foram alcançadas no momento em que estavam envolvidos na atividade. No caso de Leonardo, a ideia relatada não tem relação direta com suas atividades, mas de alguma maneira, como podemos ver na passagem seguinte, nos permite perceber como se dá o imbricamento entre trabalho e não trabalho.

Já, já pensei bastante [sobre o trabalho, após o final da jornada], atualmente eu estou mais ocioso nesse sentido. Mas sempre. Deixa eu dar um exemplo: na hora que eu comecei a academia, pensei "seria legal se tivesse um aplicativo onde eu conseguisse ver o treino e tal. A cabeça não para, né”? (Leonardo, 17/07/2014).

Assim como não acreditamos ser possível uma separação entre vida e trabalho, também compreendemos que nossa análise em relação a essa categoria de profissionais recai sobre o momento histórico atual, cuja lógica de configuração do trabalho demanda, sobretudo, o uso das subjetividades dos trabalhadores como fator de produção. Assim, é esperada a articulação entre vida profissional e vida pessoal, fazendo com que os trabalhadores, mesmo fora do escritório ou com o computador desligado, estejam produzindo, ainda que não seja com o foco sobre o seu trabalho remunerado. De modo que, para Boltanski e Chiapello (2009, p.193) "num mundo conexionista [...] torna-se difícil fazer a distinção entre o tempo da vida privada e o tempo da profissional, entre jantares com amigos e jantares de negócios, entre elos afetivos e relações úteis etc.".

Durante os períodos de férias, descanso e feriados, também é possível que esses profissionais sejam contatados por seus clientes ou empregadores, para resolver problemas, tirar dúvidas sobre projetos, concluir atividades que dependem de outros setores ou equipes. É o caso de Luan, 26 anos, branco, solteiro e sem filhos. Graduado em Engenharia de Produção, trabalhou em uma multinacional de TI por quase dois anos. Durante um ano e meio, trabalhou como estagiário no setor de Business 
to Bussiness, depois, na mesma empresa, foi contratado como CLT, alocado no setor em que trabalhava com vendas e prospecção de novos clientes - comercial. Mas a pressão do setor e a incompatibilidade de objetivos (dele e da empresa) o motivou a sair da empresa. Na época da entrevista, estava estudando para concurso público. Mas sua experiência nos ajuda a apreender as situações em que o tempo de descanso é apreendido pelo trabalho.

[...] o melhor exemplo disso foi no dia 24 de dezembro que eu tinha voltado para minha cidade, para o Natal [comemorar as festas natalinas]. E tinha que mandar um contrato para o cliente, porque o departamento dele de contrato iria fechar. E não iria receber mais nenhum contrato e o nosso contrato não tinha ficado pronto. Eu tive que ficar ligando, já era... Já não era para eu estar trabalhando dia 24 de dezembro e estava lá [eu] trabalhando ainda, porque tinha que mandar esse contrato. Eu consegui mandar às seis e meia da tarde. (Luan, 26/03/2015).

Os entrevistados mobilizam discursos justificadores que procuram argumentar a frequência com que são acionados para trabalhar, ou a liberdade e capacidade de escolha para realizar o trabalho. Parece-nos que há uma tendência, em alguns casos, de minimizar ou naturalizar essas ocorrências. Como narrado por Leonardo, quando questionado sobre a existência de casos em que fora solicitado durante as férias ou em períodos de descanso para resolver algum tipo de problema. "[...] um pouquinho. Eu estava fazendo um pacote da promoção e fui um pouquinho acionado com relação a algumas dúvidas.”

Santiago (2012) debate as teses que engendram o conceito de teletrabalho, entre elas aquela relativa ao imbricamento entre os tempos de trabalho e não trabalho. $\mathrm{O}$ autor questiona o argumento que aponta para as mudanças, na contemporaneidade, na forma de experienciar os tempos de trabalho e não trabalho. Retomando a primeira revolução industrial, Santiago mostra que a deslocalização do trabalho dos domicílios em direção às fábricas separou execução da concepção e criou um novo tipo de trabalhador: especializado, dependente direta e indiretamente da padronização dos tempos e movimentos estabelecidos pelos supervisores e gerentes. A lógica de jornada de trabalho rígida implicou uma suposta eliminação das porosidades entre tempo de trabalho e de não trabalho. Suposta, pois, para o autor, o fato de a deslocalização do trabalho da casa para a fábrica ter, aparentemente, separado tempo de trabalho e não trabalho, não significa ser possível conceber que se trate de duas esferas executadas em tempos diferentes. No fordismo-taylorismo a separação do tempo de trabalho e tempo da vida é um pressuposto fictício, afinal não é possível supor que o trabalhador não levasse trabalho - na forma de pensamento fragmentado ou por meio de questões pontuais - para o âmbito da casa. Nesse sentido, argumenta que a casa nunca esteve separada do mundo do trabalho.

O que precede significa que os trabalhadores tayloristas realizaram sua jornada de trabalho (produção da força de trabalho), mas nunca pararam de pensaragir em outras áreas de suas vidas. Da mesma forma, quando chegaram em casa (reprodução da força de trabalho), eles não podiam parar de pensar em 
seu trabalho, e eles não podiam porque - como Bourdieu colocou - os seres humanos não são idiotas culturais (SANTIAGO, 2012, p. 37, tradução nossa). ${ }^{10}$

Entendendo o teletrabalho enquanto uma nova forma de organização do trabalho da sociedade contemporânea, o autor insiste em apontar que tal modalidade não representa um novo fenômeno, "mas uma expressão distinta entre a relação do mundo do trabalho e do mundo da vida" (SANTIAGO, 2012, p. 37). Nesse sentido, é enfático ao afirmar que o debate sobre o tempo do trabalho é mais importante que problematizar os espaços de trabalho, pois considera o trabalho uma construção cultural com níveis diferenciados de expressão física. Defende que as interferências do tempo do trabalho sobre o tempo da vida significariam, portanto, um acordo cultural que permitiria ao trabalhador remoto organizar-se, mas que na prática não seria fácil separá-los porque o tempo da vida cotidiana inclui trabalho.

Romualdo tem 36 anos, é casado e tem um filho. É graduado em Sistema de Informação e pós-graduado em Sistema Web. É sócio proprietário - com mais outros dois sócios - de uma empresa de TI, que, no período da entrevista, existia há oito meses. A empresa presta serviços para uma grande Imobiliária em São Carlos, administrando toda a base de dados da cliente. Em 2013, ano anterior à entrevista, organizou-se para tirar 15 dias de férias; sobre essa experiência nos relatou o seguinte:

[qual foi a sua última férias?]. (Risos). Ano passado. Ano passado? É! Eu tirei quinze dias... duas semanas. Eu fui para casa do meu sogro que mora em Minas Gerais, mas antes dessa já fazia uns três anos que eu não tirava férias. [...] Eu voltei correndo (risos) [antes do fim das férias]. Aconteceram uns problemas. Nós tínhamos uma ferramenta com outra empresa e deu alguns problemas com o site e eu antecipei em dois dias, acabei voltando um pouco antes. Até o dia que eu fiquei sem telefone foi o dia que ele [o sócio] me ligou. Foi bem no dia que acabou a bateria do meu celular e eu falei pra minha mulher: "ah, deixa meu celular, acabou a bateria. Vamos para o zoológico". De lá a gente foi para o shopping e cheguei 10 ou 11 horas [da noite] e eu esqueci até de ligar [o aparelho]. No outro dia, a primeira coisa que eu fiz foi ligar o computador e vi que tinha dois, três e-mails dele [do sócio] e três ligações. Todo dia eu olhava, naquele dia que eu não olhei... aí eu liguei pra ele [que] falou: "olha, aconteceu um problema aqui". [...]. Eu falei "pode começar a desenvolver aí do zero esse sistema e amanhã ou depois eu estou aí". Eu peguei minha família e voltamos embora. [E a sua esposa?] Ela entende, ela sabe. (Romualdo, 29/07/2014).

10 No original, leia-se: "Lo anterior quiere decir que los trabajadores tayloristas cumplían su jornada de trabajo (producción de la fuerza de trabajo), pero nunca dejaban de pensar-actuar en otros espacios de su vida. De igual forma, al llegar a casa (reproducción de la fuerza de trabajo) no podían dejar de pensaractuar en su trabajo, y no podían porque - como lo planteó Bourdie - lo seres humanos no somos idiotas culturales". 
Desligar-se do trabalho, vivenciar e concluir os momentos de descanso sem interferência dos compromissos de trabalho parece não ser mais possível, o que nos levar a questionar: é o trabalho o principal protagonista dessas histórias e vidas?

Sociabilidade e solidão: vantagens e desvantagens do home office

Rafael tem 24 anos, é solteiro e não tem filhos. No momento da entrevista, cursava o último ano da graduação em análise e desenvolvimento de sistemas. Mas sua vida profissional começou bem antes de iniciar a graduação. Seu primeiro trabalho, um estágio na área de tecnologia, possibilitou o aprendizado sobre desenvolvimento e muitos outros temas que só aprenderia no segundo ano de faculdade. Entre a primeira experiência de trabalho e a atual, Rafael passou por cinco outras empresas, permanecendo, em média, um ano em cada uma delas. Foi estagiário na primeira empresa de desenvolvimento de softwares, depois atuou como programador em outras duas empresas (como celetista) e chegou a trabalhar, por pouco tempo, em home office, para uma grande multinacional da área de TI. $\mathrm{Na}$ empresa atual - com sede em Londres-UK -, é analista programador, vinculado como PJ.

O entrevistado destaca alguns pontos positivos de trabalhar em casa, a começar pela economia de tempo com o deslocamento até a empresa, mas a perda de sociabilidade, principalmente aquela própria do espaço de trabalho, nem sempre compensa a "liberdade" do trabalho em casa. Na percepção de Rafael:

O home office tem bastante vantagens, principalmente em relação à tranquilidade, porque você tem uma flexibilidade no horário, você pode acordar um pouco mais tarde. Se fosse numa empresa eu teria que acordar mais cedo. Tem algumas vantagens, principalmente em relação a isso, você pode ficar numa roupa mais casual, se você acordar e quiser trabalhar de pijama você pode trabalhar de pijama, ninguém vai ligar. Então, tem todas essas vantagens, a flexibilidade, a tranquilidade de você fazer as coisas no seu tempo. Só que tem as desvantagens, por exemplo, você sente falta de ter alguém ao lado, para conversar. Por mais que você tenha suas amizades, por mais que você frequente outros lugares, home office vai ser oito horas do dia. Mesmo aqui, eu morando com os meus pais, eles ficam trabalhando e eu fico sozinho aqui em casa. São oito horas do dia que você fica sozinho sem ninguém pra conversar [...]. Às vezes, você está com algum problema no trabalho é mais fácil se você tiver alguém ao lado. Só que trabalhar no local de trabalho tem suas desvantagens também, principalmente em tempo, porque, às vezes, você perde tempo para chegar, mas tem essa vantagem de você estar com outras pessoas, poder tirar suas dúvidas, poder estar se relacionando com outras pessoas no dia a dia. O que também é bom. (Rafael, 18/11/2014).

Para Rafael trabalhar em casa reflete sobre a sociabilidade promovida nos espaços de trabalho e aproxima, também, do significado atribuído por Sennett (1999, p. 68) ao destacar que "trabalhar em casa é a ilha última do novo regime", considerando o isolamento que, muitas vezes, o home office acaba por gerar. No 
limite, a questão é o medo da solidão que esse formato de trabalho desencadeia. Se, para o trabalhador, a perda em sair do escritório se dá em relação aos momentos de desconcentração, ricos em possibilidades de trocas, de aprendizados e em partilha de conhecimentos, para as empresas, a preocupação é com a produtividade, daí a sociabilidade torna-se importante para enriquecer o processo produtivo. Não à toa, a $\mathrm{CEO}^{11}$ do site de buscas Yahoo! solicitou, em 2013, a todos os seus funcionários que trabalhavam em home office, retornarem aos escritórios da empresa. $\mathrm{O}$ argumento foi justamente o da importância da sociabilidade para o processo de criação. Segundo o memorando que circulou na época, a executiva destacou que "as melhores ideias e decisões vêm das discussões no corredor e na cafeteria”. ${ }^{12}$

\section{Considerações finais}

Os aspectos positivos do trabalho remoto, usualmente mencionados pelos profissionais, referem-se à economia de tempo em preparar-se e deslocar-se para o trabalho, sobretudo nas grandes cidades. Esse tempo ganho, no entanto, acaba se convertendo em tempo de mais trabalho e não em tempo utilizado em nome da qualidade de vida, para lazer, prática de uma atividade física, entre outros. Como os profissionais apontam, quando trabalham em casa, é usual iniciarem a rotina de trabalho mais cedo, prolongarem até mais tarde, além de nem sempre respeitarem horários de pausa e refeições.

É preciso considerar ainda que a discussão sobre o home office não significa apenas o trabalho realizado estrita e permanentemente em casa, mas também em outros espaços que não o da empresa ou do cliente para o qual se presta serviço. É home office aquele trabalho que Castells (1999) chamou de complementar, ou seja, o trabalho que se realiza em casa após a jornada na empresa, à noite, nos fins de semana e feriados e nas férias. Apesar de os trabalhadores não apontarem como trabalho, responder e-mails e atender telefonemas sobre o trabalho, durante os períodos de descanso, é característico desta atividade profissional e faz parte da rotina de trabalho em $\mathrm{TI}$.

O trabalho em TI é vivenciado diferentemente entre trabalhadores do sexo masculino e feminino. As mulheres ainda parecem distantes de alcançar uma posição semelhante à dos homens nessa área, tanto em termos quantitativos quanto qualitativos, na medida em que ainda estão sujeitas a diversas formas de discriminação, seja de colegas, seja de superiores hierárquicos. Quando trabalham em casa, as mulheres tendem a acumular, além do trabalho em TI, comumente intensificado nesse espaço, o trabalho doméstico e o cuidado com os filhos.

11 Termo em inglês para Chief Executive Officer.

12 Em março de 2013, sites ligados á área de TI noticiaram o fim do homework na Yahoo!. Disponível em: <http://cio.com.br/gestao/2013/03/04/antes-de-proibir-teletrabalho-verifique-os-registros-da-vpn-foi-oque-fez-a-ceo-do-yahoo/>. Acesso em: 10/abr./ 2013. 
A despeito de todas as maravilhas atribuídas ao teletrabalho - muitas delas difundidas em sites e blogs que tratam do tema -, a absoluta maioria dos profissionais entrevistados não deseja trabalhar nessa modalidade de forma permanente. Uma das justificativas apontadas para isso refere-se ao fato de que trabalhar em casa representa a perda de sociabilidade propiciada pelo trabalho; nesse sentido, um sentimento comum entre os profissionais é o medo de serem esquecidos, de perderem a promoção, de os colegas pensarem que não estão trabalhando. É esse sentimento que, muitas vezes, também os leva a trabalhar mais do que se estivessem no escritório. A sociabilidade, nesse sentido, relaciona-se ao receio da invisibilidade em relação aos demais colegas e supervisores ou em relação as suas atividades de trabalho. Invisibilidade que pode incorrer em perda de reconhecimento dos pares quanto à capacidade de assumir ou manter-se em determinados cargos, prejudicando o progresso na carreira. Além disso, as relações estabelecidas com outros colegas na empresa são apresentadas de forma positiva, quer seja para ajudar no desenvolvimento das próprias atividades de trabalho, considerado o aspecto colaborativo que há no processo de trabalho, quer seja em termos de convivência no dia a dia.

\section{Referências}

ALEMÃO, Ivan; BARROSO, Márcia Regina Castro. O teletrabalho e o repensar das categorias tempo e espaço. Enfoques, v. 11, n. 1, p. 73-88, mar. 2012.

ALVES, Daniela. Gestão, produção e experiência do tempo em teletrabalho. 2008. 246f. Tese (Doutorado em Sociologia) - Universidade Federal do Rio Grande do Sul, Porto Alegre , 2008.

BRAGA, Ruy. A vingança de Braverman: o infotaylorismo como contratempo. In: ANTUNES, Ricardo e BRAGA, Ruy (org.). Infoproletários: degradação real do trabalho virtual. São Paulo: Boitempo, 2009. (Col. Mundo do Trabalho).

BOLTANSKI, Luc; CHIAPELLO, Eve. O Novo Espírito do Capitalismo. São Paulo: WMF Martins Fontes, 2009.

BRASIL. Tribunal Superior do Trabalho (TST). SUM-428 Sobreaviso. Aplicação Analógica Do Art. 244, $\$ 2^{\circ}$ DA CLT (redação alterada na sessão do Tribunal Pleno realizada em 14.09.2012) - Res. 185/2012 DEJT divulgado em 25, 26 e 27.09.2012.. Disponível em: <http://www3.tst.jus.br/jurisprudencia/Sumulas_ com_indice/Sumulas_Ind_401_450.html\#SUM-428>. Acesso em: 20 nov. 2015.

CASTELLS, Manuel. A era da informação: economia, sociedade e cultura. 2. ed. São Paulo: Paz e Terra, 1999.

CASTRO, Barbara. Afogados em contratos: as relações de trabalho no setor de TI. 324f 2013. Tese (Doutorado em Ciências Sociais) - Universidade Estadual de Campinas, Campinas, São Paulo, 2013.

Gênero e Flexibilização do Trabalho: uma análise do setor de TI. Ariús, Revista de Ciências Humanas e Artes, Campina Grande, v. 17, n. 1, p. 28-45, 2011.

COCCO, Giuseppe; VILARIM, Gilvan de Oliveira. Trabalho imaterial e produção de software no capitalismo cognitivo. Liinc em Revista, v. 5, n. 2, p. 173-190, set. 2009.

COSTA, Isabel de Sá Affonso. Teletrabalho: subjugação e construção de subjetividades. Revista de Administração Pública - RAP, Rio de Janeiro, v. 41, n. 1, p. 105-124, jan. /fev. 2007.

GONDIM, Linda M. P.; LIMA, Jacob Carlos. A pesquisa como artesanato intelectual. Considerações 
sobre método e bom senso. São Carlos: EdUFSCar, 2006.

HUWS, Ursula; JAGGER, Nick; O’REGAN, Siobhan. Teleworking and Globalization. Towards a methodology for mapping and measuring the emerging global division of labour in the information economy. Bringhton,UK: The Institute for Employment Studies, 1999. Disponível em: <http://www. employment-studies.co.uk/system/files/resources/files/358.pdf >. Acesso em: 20 nov. 2015.

LAZARATTO, Maurizio; NEGRI, Antônio. Trabalho imaterial: formas de vida e produção de subjetividade. Rio de Janeiro: DP\&A, 2001.

MARTINS, Amanda Coelho. O trabalho dos estilistas de moda: um convívio entre o glamour e o precário. In: SEMINÁRIO NACIONAL DE SOCIOLOGIA E POLÍTICA, VIII. 2017, Curitiba-PR.

OBSERVATÓRIO SOFTEX. Software e Serviços de TI: A indústria brasileira em perspectiva - n.2 / Observatório SOFTEX. - Campinas: [s.n.], 2012. Disponível em <http://assespro.org.br/biblioteca/ documentos/2012-06-observatorio-softex-a-industria-brasileira-de-software-e-servicos-de-ti-emperspectiva-volume-2/>. Acesso em: fevereiro 2013.

OLIVEIRA, Daniela Ribeiro; MARTINS, Amanda Coelho. Espaços virtuais do trabalho em TI: as frágeis fronteiras entre vida profissional e pessoal. In: Flexíveis, virtuais e precários? Trabalhadores em tecnologias de informação. Curitiba: Ed. da UFPR, 2017 (no prelo).

PINA, Marcos Roberto Mariano. Empreendedores da cena noturna: uma análise do trabalho de Promoters de eventos artístico-musicais na cidade de São Paulo. 2014. Dissertação (Mestrado em Sociologia) - Universidade Federal de São Carlos, São Carlos, São Paulo, 2014.

PIRES, Aline Suelen. A "geração Y" e o discurso da flexibilidade geracional entre trabalhadores da área de Tecnologia da Informação (TI). In: ENCONTRO ANUAL DA ANPOCS, 40. 2016. Anais. Caxambu: Anpocs, 2016. Disponível em: <http://www.anpocs.com/index.php/papers-40-encontro/st-10/st048/10151-a-geracao-y-e-o-discurso-da-flexibilidade-geracional-entre-trabalhadores-da-area-de-tecnologiada-informacao-ti/file>. Acesso em: maio 2017.

Juventude(s) e o trabalho na área de TI: uma discussão sobre o discurso da flexibilidade geracional. In: Flexíveis, virtuais e precários? Trabalhadores em tecnologias de informação. Curitiba: Ed. da UFPR, 2017 (no prelo).

ROSENFIELD, Cinara Lerrer; ALVES, Daniela Alves de. Autonomia e Trabalho Informacional: o Teletrabalho. Dados, Revista de ciências sociais, Rio de Janeiro, v. 54, n. 1, p. 207-233, 2011.

ROSENFIELD, Cinara Lerrer. Trabalho decente e precarização. Tempo Social, Revista de Sociologia da USP, São Paulo, v. 23, n. 1 p. 247-268, 2011.

SENNETT, Richard. A corrosão do caráter. Rio de Janeiro: Record, 1999.

SANTIAGO, Gerardo Tunal. Reflexiones en torno a los analisis sobre el teletrabajo. Trabajo y Sociedad, n. 19, p. 196-213, 2012. Disponível em https://ww w.google.com $. b r / s e a r c h ? q=R e f l e x i o n e s+e n+t o r n o+a+$ los+analisis+sobre+el+teletrabajo\&oq=Reflexiones+en+torno+a+los+analisis+sobre+el+teletrabajo\&aqs $=$ chrome..69i57.687j0j7\&sourceid=chrome\&ie=UTF-8. Acesso em: abril 2015

SILVA, Glaucia Aparecida. “A ideia é o valor mais importante do Design”: trabalho criativo no Design Gráfico. 2014. Dissertação (Mestrado em Sociologia) - Universidade Federal de São Carlos, São Carlos, São Paulo, 2014.

ZARIFIAN, Philippe. Engajamento Subjetivo, disciplina e controle. Novos Estudos - CEBRAP, São Paulo, n. 64, p. 23-31, nov. 2002.

ZANON, Breilla. Rede, coworking e emancipação intangível: um olhar sobre a flexibilidade, biopolítica e subjetividade a partir da reestruturação produtiva. 2015. 114f. Dissertação (Mestrado em Ciências Sociais) - Universidade Federal de Uberlândia, Uberlândia, Minas Gerais, 2015. 
Sites

ADORO HOMEOFFICE. Disponível em: <http://adorohomeoffice.com.br/>.

GO HOME. Disponível em: <https://www.gohome.com.br/>.

NÔMADES DIGITAIS. Disponível em: <http://nomadesdigitais.com/comece-por-aqui/>.

Recebido em 15/02/2016

Aceito em 12/07/2017 